\title{
Development of Social Recommendation GIS for Tourist Spots
}

\author{
Tsukasa IKEDA \\ Graduate School Student, \\ Graduate School of Information Systems, \\ University of Electro-Communications \\ Tokyo, Japan
}

\author{
Kayoko YAMAMOTO \\ Associate Professor, \\ Graduate School of Information Systems, \\ University of Electro-Communications \\ Tokyo, Japan
}

\begin{abstract}
This study aims to develop a social recommendation media GIS (Geographic Information Systems) specially tailored to recommend tourist spots. The conclusions of this study are summarized in the following three points. (1) Social media GIS, an information system which integrates WebGIS, SNS and recommendation system into a single system, was conducted in the central part of Yokohama City in Kanagawa Prefecture, Japan. The social media GIS uses a design which displays its usefulness in reducing the constraints of information inspection, time and space, and continuity, making it possible to redesign systems in accordance with target cases. (2) The social media GIS was operated for two months for members of the general public who are more than 18 years old. The total numbers of users was 98 , and the number of pieces of information submitted was 232. (3) The web questionnaires of users showed the usefulness of the integration of Web-GIS, SNS and recommendation systems, because the functions of reference and recommendation can be expected to support tourists' excursion behavior. Since the access survey of log data showed that about $35 \%$ of accesses were from mobile information terminals, it can be said that the preparation of an optimal interface for such terminals was effective.
\end{abstract}

Keywords-Social Recommendation GIS; Web-GIS; Social Media; SNS; Recommendation Systems

\section{INTRODUCTION}

In recent years the transformation of Japan to an information-intensive society is progressing, and a variety of information is being transmitted using the internet. Similarly, a variety of information is also being transmitted using the internet in the field of tourism, and the internet has become a primary information source for planning tourist trips and searching for information about the area of a destination. However, due to the large amount of information, and the variety of types of information, it is difficult for users to appropriately select and acquire necessary information by themselves. In particular, the amount of information submitted and made public about tourist spots in urban areas is very large compared to that for regional tourist spots, and it is difficult for people who do not have much knowledge of or acquaintance with the places concerned to efficiently obtain information necessary for taking tourist trips. Therefore, a recommendation system for guiding users to appropriate information is necessary.

Meanwhile, Japanese society has become such that nowadays, anyone, anywhere, anytime can use an information system to easily transmit, receive, and share information, and through the effective use of information systems, information possessed by ordinary people can be collected and accumulated. Of the information possessed by people involved in tourist spots as supporters of tourist services, local residents, and people who have visited the tourist spots as tourists, "experience-based knowledge" is the part that exists as "tacit knowledge" that is not visualized if it is not communicated to others. Therefore, by using an information system to change this "experience-based knowledge" into "explicit knowledge" which can be accumulated, organized, utilized, and made public, collecting the knowledge, and having users share the knowledge with each other, it will become possible for users to efficiently obtain necessary information and to go on fulfilling tourist excursions.

Based on the above-mentioned background, the aim of the present study is to uniquely develop a social recommendation GIS (Geographic Information Systems) which integrates a Web-GIS, an SNS, and a recommendation system, and is designed for recommending tourist spots, in order to support users' efficient acquisition of information about tourist spots in urban tourist areas, about which a variety of information is transmitted, by enabling information to be accumulated, shared, and recommended.

Further, the system that is developed is also operated and evaluated, and measures to improve the system are identified. The aim is for the social recommendation GIS of the present study to transform information about tourist spots which is tacit knowledge into explicit knowledge and to accumulate and share the information so that the appeal of the tourist spots is communicated. In addition, the aim is for the social recommendation GIS to support users' efficient acquisition of information about tourist spots by guiding users to appropriate information from among the enormous amount of varied information available.

\section{RELAED WORK}

The present study is related to three fields of research: (1) Research concerning tourism support systems and methods; (2) Research concerning systems and methods that recommend places such as tourist spots; and (3) Research concerning the development of social media GIS. Following are examples of previous studies in these related fields which focused on tourist information and regional information. In (1) Research concerning tourism support systems and methods, Ishizuka et 
al. (2007) [1] proposed a method of searching for similarities in data on movement paths of tourists based on location information and text information related to the location information. Kurata (2012) [2] developed a sightseeing route automatic generation system which utilized a Web-GIS and a genetic algorithm. Kawamura (2012) [3] proposed using a standard tag related to tourism in an SNS, set up a website, and organized tourist information about Hokkaido on the internet.

In (2) Research concerning systems and methods that recommend places such as tourist spots, Kurashima et al. (2011) [4] proposed a method for recommending travel routes that utilizes geotags in a photo-sharing website, and Van Canneyt et al. (2011) [5] proposed a system for recommending tourist attractions. Batet et al. (2012) [6] proposed a system for recommending tourist spots using a multi-agent system, and Uehara et al. (2012) [7] proposed a system which recommends tourist spots by extracting tourist information from the Web and calculating similarities between tourist spots based on multiple feature vectors. Further, among research concerning LBSN (location-based social networks), research concerning recommendation of points of interest (POIs) also belongs to the field of research about systems and methods that recommend places such as tourist spots. Representative examples of research concerning recommendation of POIs are the study by $\mathrm{Yu}$ and Chang (2009) [8] in which they proposed a POI recommendation system which supports trip planning, the study by Noguera et al. (2012) [9] in which they proposed a POI recommender system based on location information about present location, and the study by Baltrunas et al. (2011) [10] in which they proposed a POI recommender system based on location information and user preferences. Ye et al. (2011) [11] and Ying et al. (2012) [12] proposed POI recommendation methods based on location information, user preferences, and social networks. Similarly, Bao et al. (2013) [13] proposed a recommender system based on such things. Yuan et al. (2013) [14] proposed a POI recommendation method which took spatio-temporal information into account, and Liu et al. (2013) [15] proposed a POI recommendation method which took changes in user preferences into account.

In (3) Research concerning the development of social media GIS, using a Web-GIS, an SNS, and a wiki, Yanagisawa and Yamamoto (2011) [16] developed a system for accumulating local knowledge in local communities, and Nakahara et al. (2012) [17] developed a system for supporting communication concerning local knowledge in local communities. Further, using a Web-GIS, an SNS, and Twitter, Yamada and Yamamoto (2013) [18] developed a system for information exchange between regions, and Okuma and Yamamoto (2013) [19] developed a system for accumulating urban disaster information.

However, in the previous research mentioned above, there is no system that integrates a Web-GIS, an SNS, and a recommendation system. In the present study, we develop a system which integrates a Web-GIS, an SNS, and a recommendation system, and this makes the system unique. Further, support for efficient acquisition of information about tourist spots which takes into account the preferences of each user is enabled by making accumulation, sharing, and recommendation of information possible in the one system, and in this respect, a synergistic effect of integrating the three above-mentioned applications is obtained. This demonstrates the usefulness of the system. Further, the present study also focuses on information exchange between users - something that until now has not been taken into account very much in studies involving just a recommendation system - and includes a recommendation system in an SNS. Through this, both effective recommendation of tourist spots to each user and information exchange between users which utilizes SNS communication functions are enabled in the one system, and this is another reason the system is useful.

\section{RESEARCH OUTLINE AND METHOD}

In the present study, research is conducted according to the following outline and method. Firstly, a social recommendation GIS which specializes in the aim of the present study is uniquely designed (Section IV) and developed (Section V). Next, anticipating users are the general public who are more than 18 years, an operation test and operation of the social recommendation GIS (Section VI) are conducted. Further, the system is evaluated and measures for improving use of the system are identified (Section VII). Anticipating that each user will use the system for about a month, an operation test and an evaluation of operation test are conducted, and then actual operation is conducted. In addition, web questionnaires are given to users, access is analyzed using log data during the period of actual operation, and submitted information is analyzed. Based on the results of these steps, the system is evaluated, and measures to improve the system in order to more effectively support people taking tourist trips are identified. The central part of Yokohama City in Kanagawa Prefecture was selected as the region for operation. One reason is that this area is a popular urban tourist area, so many tourists visit it; therefore, a lot of information about the area is submitted by people and published, with the result that it is difficult for tourists to efficiently obtain necessary information about the area. A further reason is that since this area has many kinds of tourist spots, the system of the present study can be used to recommend tourist spots that are suited to the preferences of various users.

\section{DESIGN OF THE SYSTEM}

\section{A. System Features}

As shown in Fig. 1, the system proposed by the present study is formed by an integration of three applications - a Web-GIS, an SNS, and a recommendation system. The primary reason for integrating these three applications is that if only a Web-GIS is used, a system is limited to unilateral transmission of information using a digital map; therefore, an SNS was integrated with a Web-GIS to allow interactive transmission and reception of information. The second reason is that, as will be described in detail in Section IV.B.2), in the present study, Environmental Systems Research Institute, Inc.'s (ESRI's) ArcGIS Server is used as the Web-GIS; however, a recommendation system cannot be directly included in the ArcGIS Server. Therefore, the Web-GIS and the recommendation system were included in the SNS to enable the three applications to be integrated together. Accordingly, integrating the three applications - that is, the Web-GIS, the SNS, and the recommendation system - enables 
the benefits outlined below to be realized in the one system, and therefore, a synergistic effect of integrating the three applications can be obtained.

Specifically, management and visualization of submitted information on the digital map of the Web-GIS, limitation of users by the uniquely developed SNS, and information sharing and exchange between a limited group of users are enabled. Further, users can submit, view, and evaluate information while gaining a grasp of geographic information related to tourist spot information on the digital map. Moreover, thanks to the inclusion of the recommendation system, information suited to the preferences of each user can be given more priority, when information that has been accumulated and shared is provided to users using the digital map. Therefore, even when the system is operated in the long term and an enormous amount of information has been accumulated, each user can be introduced to appropriate information, and it can be anticipated that the system will support efficient acquisition of information about tourist spots. Accordingly, the system's usefulness, mentioned in Section II, can be described in detail in the following manner.

\section{1) Easing of constraints concerning information inspection}

As a situation in which information inspection might be restricted, a situation in which a variety of information is submitted and transmitted, the amount of information becomes excessive, and users have difficulty efficiently selecting and obtaining the necessary information can be imagined. Therefore, in order to ease constraints on inspecting information, a recommendation system is included in the system of the present study. This allows the system to appropriately guide each user to information about tourist spots that is suited to their preferences from among a large amount of information in a short time.

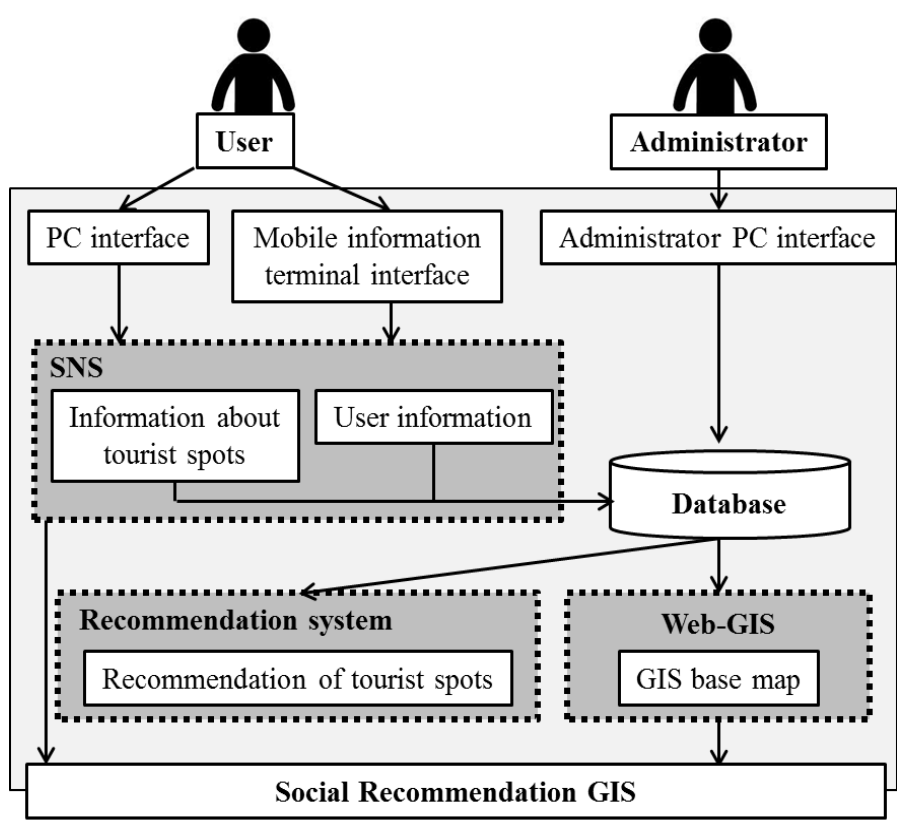

Fig. 1. System design of social recommendation GIS

\section{2) Easing of time and spatial constraints}

As a situation in which time and spatial constraints might arise, a situation in which connection to the internet is not possible can be imagined. In order to ease such constraints, in addition to a PC interface, an interface for mobile information terminals is also provided, so the system can be used anytime regardless of whether a user is indoors or outdoors. Thanks to this, even when users are in the middle of a tourist trip, they can use the functions for viewing and recommending information about tourist spots independent of time and spatial constraints in order to obtain support for efficiently acquiring information about tourist spots.

3) Easing of constraints concerning continuous operation of the system

In order to maintain an environment in which tourist information can be submitted, view, and recommended without constraints on time and place, thanks to the features outlined above in 1) and 2), a system design which enables management of information submission is necessary. Further, in the case where the system is designed as one in which anyone can participate, if there is no system that allows the management of submitted information, there is a risk that system operation which conforms with the aims of the system may be difficult when inappropriate information is submitted. However, in the system of the present study, users with malicious intent can be identified, because submitted information is managed in a centralized manner using a database and accounts are managed using the SNS; therefore, long-term operation of the system is possible.

Further, the information terminals focused on for use with the system of the present study are PCs and mobile information terminals. In the latter category, smartphones and tablet-type terminals (which have rapidly come into wide use in recent years) are focused on for use with the system. Both these types of mobile information terminals have touch panels with large screens, which means they are easy to use when dealing with digital maps, and both types allow connection to the internet from anywhere via cellular phone data communication networks. Therefore, they can achieve easing of the time and spatial constraints mentioned above.

\section{B. System design}

\section{1) System configuration}

The social media GIS of the present study is formed using three servers - a web server, a database server, and a GIS server. The web server mainly performs processing related to the SNS, and accesses the GIS server and the database server to integrate each of the functions. The SNS is implemented using JavaScript and PHP, and the recommendation system is implemented using PHP. The database server is managed using MySQL, and accumulates submitted information collected through the SNS. For the web server and the database server, the rental server of the information technology center of the organization to which the authors belong was used. For the GIS server, as the OS, Microsoft Corporation's Windows Server 2008 was used, and as the GIS server software, ESRI's ArcGIS Server 10.0 was used. 


\section{2) Web-GIS}

In the present study, for the Web-GIS, ESRI's ArcGIS Server 10.0 was used, and for the GIS base map of the WebGIS, the SHAPE version (Rel.8) of Shobunsha Publications, Inc.'s MAPPLE10000, which is part of their MAPPLE digital map data and includes detailed road system data, was used. As the map that was superimposed with this digital map data, the user interface of Google Maps was used. Among the options provided by ESRI that are ArcGIS Server 10.0 API targets, the Google Maps user interface is the one that has been used the most in previous studies in fields related to the present study. Concerning the superimposition of MAPPLE10000 (SHAPE version) and Google Maps, Google Maps employs the new geodetic system coordinates, while MAPPLE10000 conforms to the former geodetic system coordinates; therefore, ArcTKY2JGD, which is provided by ESRI as product support, was used to convert the MAPPLE10000 geodetic system coordinates to the new coordinates. Furthermore, editing was performed such that information about the region for operation could be input using ArcMap 10.0.

\section{3) $S N S$}

In the present study, an SNS was selected as the social media for integration with the Web-GIS and the recommendation system. The SNS was uniquely designed and developed to suit the objectives of the system. An SNS was chosen because in contrast to other forms of social media, if an SNS is used the system can be uniquely designed and developed in a way that best suits the objectives of use, and detailed system configuration can be performed in a unique manner to suit regional characteristics of the region in which the system is to be operated. Further, as mentioned in Section IV.A, developing our own unique SNS enabled the information transmission of the system to be interactive, and enabled the recommendation system to also be integrated into the system.

Firstly, features such as those relating to registering and publishing user information and to submitting, viewing, and recommending information were uniquely designed to suit to the objectives of the present study. Next, since in this system it is desirable that users voluntarily communicate with each other, in contrast to ordinary SNSs, friend registration and community functions were not designed, and as methods for communication, comment function and button functions were designed. The comment function is used for communication between users and for providing additions related to submitted information. Concerning the button functions, two buttons were designed - one for "I want to go there" and one for "I didn't know that". These buttons are used for simple communication and for evaluating submitted information. Of the button functions, a ranking function was also added to the "I want to go there" button function. In order to show clearly what kinds of submissions are attracting attention from users, submissions are shown in order of popularity on the submitted information ranking page of the user screen.

\section{4) Recommendation system}

There are three methods for recommendation systems collaborative recommendation, content-based recommendation, and knowledge-based recommendation (Jannach et al., 2012) [20], and in this system, knowledgebased recommendation is used. A reason for this is that knowledge-based recommendation can solve the cold start problem. The cold start problem is that it is difficult to make appropriate recommendations for users new to using the system, and difficult to recommend items which have been newly introduced to the system as items for recommendation. Concerning the problem of difficulty in making appropriate recommendations to new users, Kamishima (2008) [21] pointed out that if knowledge-based recommendation is employed, users directly write their own user profiles themselves, so the problem does not arise. Further, concerning the difficulty of recommending newly introduced items, Kamishima (2008) [21] pointed out that when content-based recommendation or knowledge-based recommendation is employed, if there are user profiles, even new items can be recommended without a problem, using their feature vectors as hints.

Further, this system is for use with ordinary people. Therefore, in the creation of user profiles based on user preference information, it is desirable to use a question format which is clear and intuitively easy to understand. Therefore, the question items are asked using values in five stages of from 1 to 5 , and user profile vectors are created. Similarly, regarding tourist spot evaluation information, a submitter of new tourist spot information is asked questions about each evaluation item using values in five stages of from 1 to 5 , and tourist spot feature vectors are created. Thus, for the purpose of dealing with the above-mentioned cold start problem as well, in this system a setting is used that means users must input evaluation information when they submit information about a tourist spot. Further, when appealing to people to use the system, this was explained in the operating instructions that were distributed, and people were asked to input evaluation information.

Based on the user profiles of users and tourist spot feature vectors that have been created, degree of similarity is calculated using Equation (1), and tourist spots with a high degree of similarity are recommended.

$$
\operatorname{Sim}_{j}=\frac{\sum_{i=1}^{n} U_{i} * S_{i j}}{\sqrt{\sum_{i=1}^{n}\left(U_{i}\right)^{2}} * \sqrt{\sum_{i=1}^{n}\left(S_{i j}\right)^{2}}}
$$

$\operatorname{Sim}_{j}$ : Degree of similarity

$U_{i}$ : User preference information

$S_{i j}$ : Tourist spot evaluation information

$i$ : Question item number

$j$ : Tourist spot number

\section{5) Management of submitted information}

As mentioned in Section IV.A regarding the easing of constraints concerning continuous operation of the system, a system design which enables management of submitted information is necessary. Therefore, this system aims for longterm operation, and is designed such that no restrictions are imposed when submitted information is made public to all users, but in the case where an administrator determines that a posting has been made by a user with malicious intent or determines that submitted information does not suit the aims of the system, the administrator can exercise rights to delete accounts and delete posts. Specifically, the system is provided with a function that enables centralized management of submitted information through a database. 


\section{SYSTEM DEVELOPMENT}

\section{A. System front end}

In the present study, as is described in detail below, unique functions for users are implemented, and tourist information is accumulated, shared, and recommended.

\section{1) Information submission function}

When users wish to submit information about a tourist spot, they can click "Submit tourist information" on the initial page to move to the submission page. Items the users submit are title, tourist spot category, main text of the submission, images, information on evaluation of the tourist spot, and location information. After writing content or making selections for items other than location information, when users click the location related to the submitted information on the digital map, the location information will be input into MySQL. When the user sends their submission, the submission is complete.

\section{2) Information viewing function}

When users wish to read information about tourist spots, they can click "View" on the initial page to move to the viewing page. On the viewing page check boxes have been created for each category, so by selecting the category they wish to view, users can display a marker. When a user clicks the marker, a bubble with a link to detailed information about the tourist spot will be displayed. Further, the user can click the link in the bubble to move to a page where they can view the detailed information about the tourist spot and can use the comment function and button functions. Users can use the comment function to communicate with other users and to supplement information that has been submitted. Further, concerning the button functions, the two buttons "I want to go there" and "I didn't know that" can be used for simple communication and to evaluate submitted information. The "I want to go there" button function includes a ranking function, so submitted information can be displayed in order of popularity on the submitted information ranking page on the user screen.

\section{3) Tourist spot recommendation function}

When users use the tourist spot recommendation function, they click "Tourist spot recommendation" on the initial page to move to the tourist spot recommendation page. When a user selects the tourist spot category in which they are seeking recommendations on the recommendation page, up to a maximum of ten tourist spots that match the user's preferences will be displayed as recommendation results, together with check boxes. When the user clicks tourist spot check boxes, markers of those tourist spots are displayed on the digital map of the Web-GIS. Further, as with the viewing function, when the user clicks a marker, a bubble with a link to detailed information about that tourist spot is displayed, and the display changes to a page showing detailed information about the tourist spot which the user can view.

\section{B. System back end}

\section{1) Processing related to recommendation system}

In this system, processing for calculation of degree of similarity in the recommendation system is performed by the back end, so simply by also registering their preference information as user information, users can receive recommendations about tourist spots. From user preference information saved in the database, user profiles are created, and from information about evaluation of tourist spots saved in the database, tourist spot feature vectors are created. Further, using Equation (1) shown in Section IV.B.4), the degree of similarity of user profiles with each tourist spot is calculated. Then, up to a maximum of ten tourist spots are displayed as recommendation results for the user in descending order of similarity.

2) System for management of submitted information by administrators

Every user's submissions of information and image files are all accumulated as data in the database of the system. Administrators manage users and check submitted information using a list screen designed especially for the purpose. Administrators can take measures such as suspending accounts of users who have made inappropriate transmissions or behaved inappropriately, and if by any chance an inappropriate submission is made, administrators can delete the submission with just one click. Thanks to these features, there is no need for administrators to check whether or not inappropriate submissions of information have been made within the system; therefore, their burdened can be lessened.

\section{System interfaces}

This system has three kinds of interface - a user PC interface (Fig. 2), a mobile information terminal interface especially optimized for smartphones and tablet-type terminals (Fig. 3), and an administrator PC interface.

\section{OPERATION TEST AND OPERATION}

In accordance with the operation process in TABLE I, actual operation of the social recommendation GIS designed and developed in the present study was carried out after an operation test and an evaluation of the operation test had been conducted.

\section{A. Comparison with existing services in region of operation}

Yokohama City, the region for operation in the present study, is a popular urban tourist area, so a large amount of information about it is transmitted by various tourist information services. In order to verify the usefulness of the system within the region for operation, results of a comparison of features with existing services were summarized as shown in TABLE II. Examples of existing services that target Yokohama City are the Yokohama City official tourist information website $^{(1)}$ and the website Hamatch! SNS ${ }^{(2)}$. The Yokohama City official tourist information website transmits various information concerning tourism and introduces recommended tourist routes; however, users cannot make submissions to the site. The website Hamatch! SNS mainly accumulates and shares information, and the main purpose of these activities is to support various regional and civic activities. The only support it provides for people taking tourist trips is to display shops and places recommended by local residents by word-ofmouth on a digital map. Further, examples of services targeting the whole of Japan are the websites TripAdvisor ${ }^{(3)}$, MAPPLE Tourist Information ${ }^{(4)}$, and Jalan Tourist Information ${ }^{(5)}$, the travel word-of-mouth website 4travel.jp ${ }^{(6)}$, the website Foursquare $^{(7)}$, and "Facebook Places" ${ }^{(8)}$. These services are 
systems which also allow users to make word-of-mouth submissions about tourist spots. However, their support for tourist trips is limited to displaying tourist spot information on digital maps, introducing tourist spot information, and recommending facilities and spots near places chosen by users. They do not take the preferences of each user into account when recommending tourist spots.

Further, as shown in TABLE II, there are existing services which employ digital maps; however, the services other than the system of the present study do not use a Web-GIS; therefore, they are limited to only displaying submitted information on one digital map. They cannot employ the primary functions of a GIS which are for such purposes as digital map editing and superimposition, and information analysis. Nor are they capable of information accumulation, update, addition, correction, inspection, and so on in a digital map. In contrast, the map screen of the GIS has a layered structure (hierarchical structure); therefore, the overlay function can be used to superimpose multiple digital maps which each have different information on the base map. This function is used in the system of the present study. As described in Section IV.B.2), MAPPLE10000 (which includes detailed road system data) was used as the GIS base map, the GIS overlay function was used, and MAPPLE10000 was used in superimposition with the user interface of Google Maps. As a result, reference can be made to a detailed road system on the digital map - a road system which also includes narrow streets output from MAPPLE10000, and it is possible to precisely display tourist spot information and accurately check places related to submitted information. Further, similarly, functions for coordinate conversion and editing were used, coordinates of MAPPLE10000 were converted to suit Google Maps, and editing was performed such that information about the region for operation could be input. Therefore, compared with existing services related to the region of operation, the usefulness of the system of the present study lies in the fact that in order to support efficient acquisition of information about tourist spots, the system allows Web-GIS digital map-based information accumulation and sharing between users, WebGIS digital map-based information submission and viewing, communication between users via use of the comment function and button functions, and recommendation of tourist spots suited to the preferences of each user.

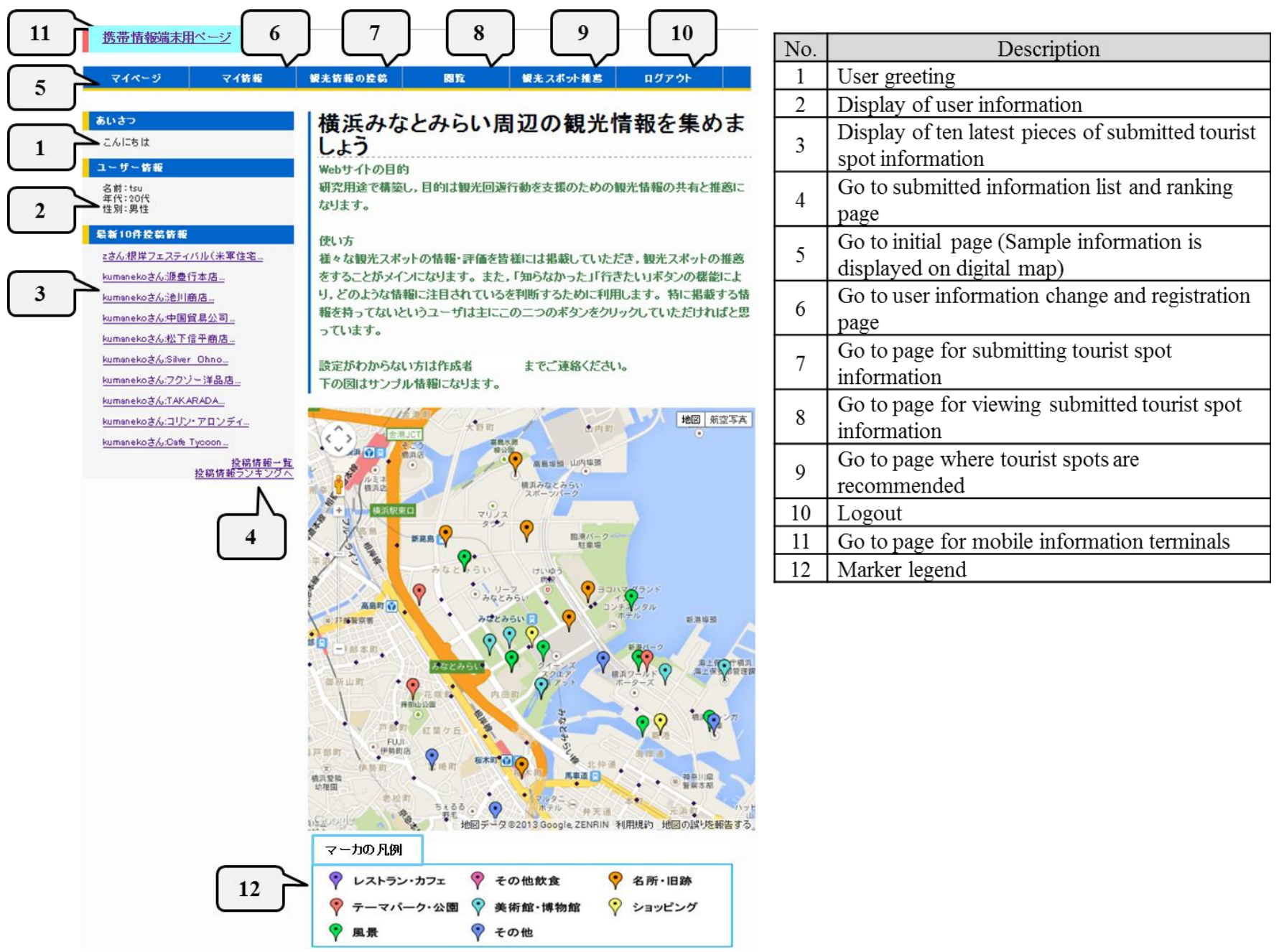

Fig. 2. PC interface and description of functions 


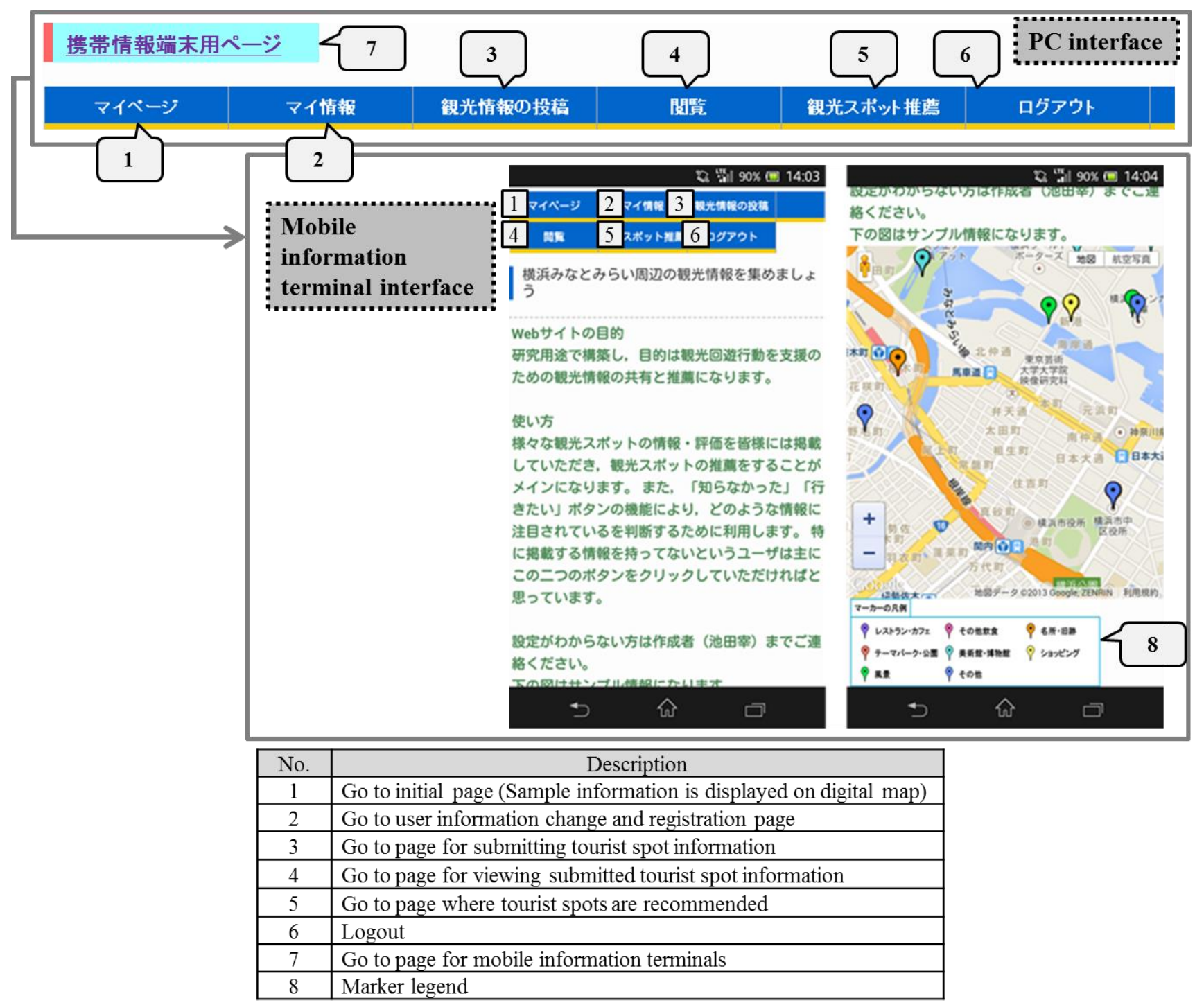

Fig. 3. Mobile information terminal interface and description of functions

\section{B. Tourist spot data}

For the present system, with reference to Yamada and Yamamoto (2013) [18] and the websites 4travel.jp and MAPPLE Tourist Information, tourist spots were divided into eight categories, and there were eleven evaluation items (Satisfaction; Access; Crowding; Scale; Worth seeing; Barrierfree; Atmosphere; Quality of attractions; Comfortableness of facilities; Exhibition contents; and Cost) for each tourist spot, to be evaluated using five ranks. Further, in order to deal with the cold start problem mentioned in Section IV.B.4) and allow the tourist spot recommendation function to be used right from the beginning of operation, it is necessary to collect and accumulate information about the main tourist spots in the region for operation. Therefore, forty-four tourist spots in the region for operation that are posted in the aforementioned website "4travel.jp" were selected, and only information about evaluation of the above-mentioned eleven tourist spot evaluation items for these forty-four spots was posted into the system of the present study immediately after start of operation.
Before posting the information, the present authors checked its validity.

\section{Anticipated users}

Two types of users were anticipated for the system, according to whether or not users had knowledge of the region for operation. It was anticipated that users with knowledge about the region of operation would mainly submit information using the submission function, supplement submitted information using the comment function, and evaluate submitted information using the button functions, thus using the system as a tool for accumulating, sharing, evaluating, and recommending information. Further, it was anticipated that users without knowledge about the region of operation would mainly view submitted information using the viewing function, evaluate submitted information using the button functions, and obtain tourist spot recommendations using the recommendation function, thus using the system as a tool for viewing, evaluating, and recommending information. 
TABLE I. OPERATION PROCESS OF THE SySTEM

\begin{tabular}{|c|c|c|c|}
\hline Process & Aim & Period & Specific details \\
\hline $\begin{array}{l}\text { 1. Survey of } \\
\text { present } \\
\text { conditions }\end{array}$ & $\begin{array}{l}\text { To understand efforts related to tourism in the } \\
\text { region for operation (Yokohama City) }\end{array}$ & $\begin{array}{l}\text { December } 2012 \text { - March } \\
2013\end{array}$ & $\begin{array}{l}\text { - Survey of government measures and internet } \\
\text { services } \\
\text { - Interviews with government departments } \\
\text { responsible, tourist associations, etc. }\end{array}$ \\
\hline $\begin{array}{l}\text { 2. System } \\
\text { configuration }\end{array}$ & $\begin{array}{l}\text { Configure the system in detail to suit the region for } \\
\text { operation }\end{array}$ & April - June 2013 & $\begin{array}{l}\text { - Define system requirements } \\
\text { - System configuration } \\
\text { - Create operation system }\end{array}$ \\
\hline $\begin{array}{l}\text { 4. Evaluation of } \\
\text { operation test }\end{array}$ & $\begin{array}{l}\text { Reconfigure the system based on results of } \\
\text { interviews with operation test participants }\end{array}$ & August - September 2013 & $\begin{array}{l}\text { - Evaluation using interviews } \\
\text { - System reconfiguration } \\
\text { - Amendment of pamphlets and operating } \\
\text { instructions }\end{array}$ \\
\hline 6. Evaluation & $\begin{array}{l}\text { Evaluate the system based on the results of } \\
\text { questionnaires, the results of access analysis which } \\
\text { used log data during the period of actual operation, } \\
\text { and the results of analysis of submitted information }\end{array}$ & $\begin{array}{l}\text { November - December } \\
2013\end{array}$ & $\begin{array}{l}\text { - Evaluation using Web questionnaires, access } \\
\text { analysis which used log data, and analysis of } \\
\text { submitted information } \\
\text { - Identification of measures for using the system } \\
\text { even more effectively }\end{array}$ \\
\hline
\end{tabular}

TABLE II. COMPARISON OF FEATURES WITH EXISTING SERVICES RELATED TO REGION FOR OPERATION

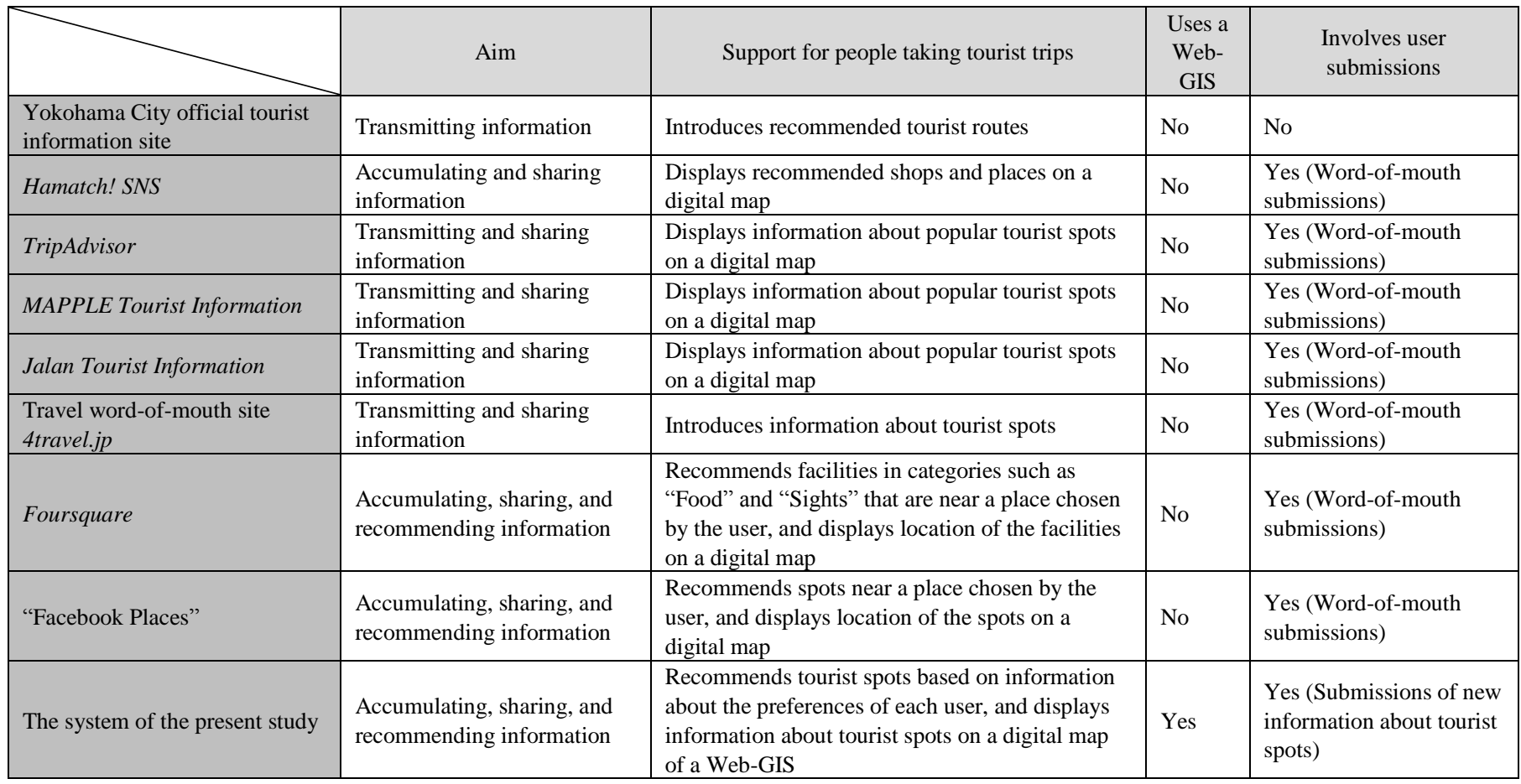

\section{Operation test and evaluation of operation test}

Before actual operation, six students in their twenties were selected as operation test participants and a two-week operation test was conducted. Based on the results of interview surveys with the operation test participants, two things for improvement were identified. One was to use a geolocation API for the recommendation page and enable information about present location to be obtained and displayed. The other was to enable selection of tourist spot categories. The system was reconfigured in regard to these two things only.

\section{E. Operation}

Use of the system was appealed for without regard to whether the appeal was aimed at people inside or outside the 
region for operation, using such means as the website of the present authors' laboratory. Further, cooperation from Kanagawa Prefecture and Yokohama City tourism-related departments, the Yokohama Convention \& Visitors Bureau (Yokohama City tourist association), and other places was gained in distributing system pamphlets and operating instructions. When users access the system for the first time, they register user information such as "User name", "E-mail address", "Age group", "Gender", and "Greeting" on the initial registration screen. In order to take into account users who did not want to make their user information public in detail as a profile, the system was designed such that users could freely choose to enter either their real name or an assumed name as their "User name", and could also choose whether to make their "Age group" and "Gender" public. When users log in after completing initial registration, they can perform operations on the submission, viewing, and recommendation screens. Further, by registering information about their preferences in "My information", users can receive recommendations of tourist spots suited to their preferences.

TABLE III shows the details of the users during the two month operation period. There were 49 male users and 49 female users, giving a total of 98 users. About $60 \%$ of users were in their twenties, while about $10 \%$ were in their thirties and $10 \%$ were in their forties. Users in their twenties to forties accounted for more than $80 \%$ of the total number of users. This is consistent with the fact that the majority of main users of regular SNSs are in their twenties to forties, as shown in the 2011 White Paper - Information and Communications in Japan [22].

Fig. 4 shows changes in the number of new users and number of new submissions in the weeks during the operation period. The total number of users at the end of the first month of operation was more than $90 \%$ of the total number of users for the whole operation period. Further, including the 44 pieces of information that the present authors submitted, as mentioned in Section VI.B, the final total number of submissions of information was 232. Although the number of new submissions made differed each week, more than 40 new submissions were made in each of Weeks 2 and 4. After having each user use the system for about one month, a Web questionnaire was given to users, and use of the system was evaluated.

\section{EVALUATION}

In this section, in accordance with the operation process in TABLE I, firstly, based on the results of the questionnaire (for which an outline of users and respondents is shown in TABLE III), an evaluation which concerned the use of the system was conducted. Next, based on the results of access analysis which used $\log$ data during the actual operation and analysis of submitted information, an evaluation concerning the aim of the system was conducted. The aim of the system is to support the efficient acquisition of information about tourist spots in urban tourist areas by enabling the information to be accumulated, shared, and recommended. Further, based on these evaluation results, measures for improving the system in order to support tourist trips more effectively were identified.

\section{A. Evaluation concerning use of the system}

\section{1) Evaluation concerning ease of use of the system}

a) Evaluation concerning information terminals employed to use the system

Concerning information terminals that users employed to use the system, the percentage of users who responded "PC only" was the highest, at about $47 \%$. Next highest was the percentage who responded "Both $\mathrm{PC}$ and mobile information terminal", at about $37 \%$, and the percentage who responded "Mobile information terminal only" was about $16 \%$. From this, it is clear that more than $50 \%$ of users employed mobile information terminals to use the system, and this is higher than the percentage of users who employed only PCs to use the system. It can be considered that this is a result of the provision of an interface optimized for mobile information terminals. Further, the percentage of users in their twenties who responded "Both PC and mobile information terminal" was about $32 \%$, and the percentage who responded "Mobile information terminal only" was about $13 \%$, so it is also clear that users in their twenties used the system from a mobile information terminal much more than did users in other age brackets. Therefore, it can be said that particularly for users in their twenties, the provision of a system which can be used anytime, anywhere from mobile information terminals such as smartphones (which have been rapidly coming into wide use in recent years) is very useful.

TABLE III. OUTLINE OF USERS AND RESPONDENTS TO THE QUESTIONNAIRE

\begin{tabular}{|c|c|c|c|c|c|c|c|}
\hline & $\begin{array}{c}\text { Aged } 10 \text { to } \\
19\end{array}$ & Twenties & Thirties & Forties & Fifties & $\begin{array}{c}\text { Sixties and } \\
\text { above }\end{array}$ & Total \\
\hline Number of questionnaire respondents (people) & 2 & 40 & 8 & 7 & 2 & 3 & 62 \\
\hline
\end{tabular}




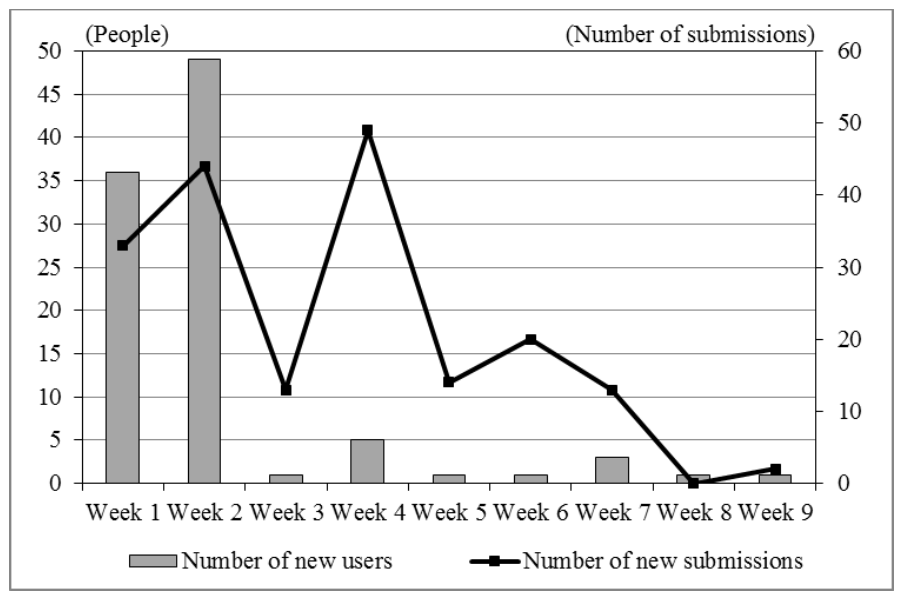

Fig. 4. Changes in the number of new users and number of new submissions during the operation period

Note: The number of submissions for Week 1 does not include the 44 pieces of information submitted by the present authors

\section{b) Evaluation concerning usefulness for tourist trips}

In order to evaluate the usefulness of the system for people taking tourist trips, users were asked whether or not the system was useful when a user was actually taking a tourist trip (visiting tourist spots, moving between tourist spots, etc.) in the region of operation. The result was that about $39 \%$ of users responded "Useful" and about $47 \%$ responded "Somewhat useful", while about $2 \%$ responded "Not very useful" and none responded "Not useful", so it can be seen that the system was highly rated. Therefore, it can be anticipated that the system of the present study will prove useful when users are actually taking tourist trips, through its support for users' efficient acquisition of information about tourist spots.

\section{2) Evaluation of the system's unique functions}

\section{a) Evaluation of use, classified by function}

Users were shown all the functions of the system, then asked to select up to two that they themselves had used the most frequently. Responses showed that the viewing function was the most frequently used function, occupying about $48 \%$ of entire frequent function usage. Next was the recommendation function, at about $27 \%$, followed by the button functions, at about 18\%. TABLE IV shows cross tabulation results for high usage frequency function and gender. "Viewing function \& Recommendation function", "Viewing function \& Button functions", and "Viewing function" were each selected by many users in the entire group - about $45 \%$, about $25 \%$, and about $13 \%$ of users, respectively. No users selected the recommendation function alone as a response. These results show that over $80 \%$ of users used the viewing function and about half the users used the combination of the viewing function and the recommendation function when using the system. Therefore, it can be considered that the system was mainly used for obtaining information about tourist spots. Further, looking at results by gender, both genders used the viewing function itself often. However, about $17 \%$ of males responded "Viewing function" and about $31 \%$ responded "Viewing function \& Button functions", and these percentages are higher than those for female respondents by about $9 \%$ and about $8 \%$, respectively. Meanwhile, the percentage of females who responded "Viewing function \& Recommendation function" was $50 \%$, about $11 \%$ higher than that for male respondents, and about $8 \%$ of females responded "Viewing function \& Comment function", while no males selected this response. These results show that there was variance between males and females for functions which were frequently used.

TABLE V shows cross tabulated results for responses in the "Total" section of TABLE IV and responses regarding the usefulness of the system for taking tourist trips, which was mentioned in Section VII.A.1).b). Among respondents who answered that the system was "Useful" or "Somewhat useful" when taking a tourist trip, respondents who selected the viewing function either alone or in combination with another function as the function or functions of the system they used the most frequently formed the largest proportion (About 31\% of respondents answered "Useful" and selected the viewing function as a most frequently used function, and about $42 \%$ answered "Somewhat useful" and selected the viewing function as a most frequently used function). Among this proportion of respondents, in particular the proportion who selected "Viewing function \& Recommendation function" as the functions they used the most frequently was the largest (About $16 \%$ of respondents answered "Useful" and selected "Viewing function \& Recommendation function" as their most frequently used functions, and about $19 \%$ answered "Somewhat useful" and selected "Viewing function \& Recommendation function" as their most frequently used functions). These results show that by using the viewing function in combination with the recommendation function in particular, information about tourist spots can be efficiently obtained, and therefore it can be anticipated that the system will be useful when users are actually taking tourist trips. Therefore, as mentioned in Section IV.A about the synergistic effect of integrating three applications - a Web-GIS, an SNS, and a recommendation system - to form one system, it can be said that it was useful to include a Web-GIS and a recommendation system in an SNS in order to enable users to access the system from either a PC or a mobile information terminal to view tourist spots and receive recommendations for tourist spots using a digital map.

\section{b) Detailed evaluation of recommendation function}

Fig. 5 shows results for responses to four question items on the recommendation function, the function which demonstrates the uniqueness of the system the most clearly. The two question items on usefulness - the usefulness of the present location display on the recommendation page and the usefulness of tourist spot category selection on the recommendation page - concern the areas for improvement that were identified based on the results of the evaluation of operation test, described in Section VI.D. The proportion of respondents who answered "Suitable" or "Somewhat suitable" concerning the suitability of the tourist spots recommended was about $74 \%$. Therefore, it can be considered that for a majority of users, suitable results were obtained when tourist spots with a high degree of similarity to preferences of users were recommended by calculating degree of similarity based on preference information registered by each user in the "My information" section of the system and information about evaluation of each tourist spot. Further, concerning the other 
three questions - that is, the questions on the suitability of the recommendations of up to a maximum of ten tourist spots, the usefulness of the present location display on the recommendation page, and the usefulness of category selection on the recommendation page - the proportion of respondents who answered "Suitable"/"Useful" or "Somewhat suitable"/"Somewhat useful" for these questions was about $77 \%$, about $77 \%$, and about $84 \%$ respectively, meaning these features were rated very highly. Based on these results, it can be said that in addition to high ratings for the tourist spot recommendation results and the feature of recommending up to a maximum of ten tourist spots (which was included in the system design from the beginning), the two features related to the improved recommendation page (present location display, tourist spot category selection), which was improved based on the results of the evaluation of operation test, also obtained high ratings.

\section{B. Evaluation of support of acquisition of tourist spot information}

1) Evaluation focusing on access count and access methods

\section{a) Outline of access analysis}

In the present study, evaluation focusing on access count and access methods was conducted by analyzing access using log data during actual operation. In the present study, a Google Analytics API was included in the program that was developed and access was analyzed. Google Analytics is a free application provided by Google, and is often used as an analysis tool. Google Analytics can be used simply by adding the API into the program of each page of a website. Once this is done, access logs can be obtained.

\section{b) Evaluation based on results of access analysis}

About $65 \%$ of all visits to the present system (a total of 3,524 visits) were those which accessed the system from a PC. However, access from mobile information terminals also comprised a not insubstantial amount of the total - about $35 \%$. Concerning this point, in the study by Yamada and Yamamoto (2013) [18], access from mobile information terminals to the social media GIS designed for information exchange between regions comprised about $12 \%$ of the total access count in 2012 . Comparing results, it is clear that the proportion of access from mobile information terminals in the present study is about three times that amount. Further, Yamada and Yamamoto (2013) [18] did not provide an interface optimized for mobile information terminals in their study, so it can be said that the provision of an interface for mobile information terminals (whose use has been spreading rapidly in recent years) in the system of the present study was useful.

TABLE IV. Functions USED THE Most FREQuently IN THE System (Up to Two SELECTED)

\begin{tabular}{|c|c|c|c|c|c|c|c|c|c|}
\hline & $\begin{array}{l}\text { Viewing } \\
\text { function }\end{array}$ & $\begin{array}{l}\text { Viewing } \\
\text { function \& } \\
\text { Comment } \\
\text { function }\end{array}$ & $\begin{array}{l}\text { Viewing } \\
\text { function \& } \\
\text { Button } \\
\text { functions }\end{array}$ & $\begin{array}{l}\text { Viewing function } \\
\& \\
\text { Recommendation } \\
\text { function }\end{array}$ & $\begin{array}{l}\text { Recommendation } \\
\text { function \& } \\
\text { Comment } \\
\text { function }\end{array}$ & $\begin{array}{l}\text { Recommendation } \\
\text { function \& } \\
\text { Button functions }\end{array}$ & $\begin{array}{l}\text { Submission } \\
\text { function }\end{array}$ & $\begin{array}{l}\text { Submission } \\
\text { function \& } \\
\text { Button } \\
\text { functions }\end{array}$ & $\begin{array}{l}\text { Submission } \\
\text { function \& } \\
\text { Viewing } \\
\text { function }\end{array}$ \\
\hline $\begin{array}{l}\text { Males } \\
\text { (36 people) }\end{array}$ & 16.7 & 0.0 & 30.6 & 38.9 & 2.7 & 2.7 & 5.6 & 0.0 & 2.8 \\
\hline $\begin{array}{l}\text { Females } \\
\text { (26 people) }\end{array}$ & 7.7 & 7.7 & 23.1 & 50.0 & 0.0 & 7.7 & 0.0 & 3.8 & 0.0 \\
\hline $\begin{array}{l}\text { Total } \\
\text { (62 people) }\end{array}$ & 12.9 & 3.2 & 27.4 & 43.5 & 1.7 & 4.8 & 3.2 & 1.7 & 1.6 \\
\hline
\end{tabular}

TABLE V. RELATIONSHIP BETWEEN USEFULNESS OF THE SySTEM FOR TAKING TOURIST TRIPS AND FUNCTIONS WITH A High USAGE FREQUENCY

\begin{tabular}{|c|c|c|c|c|c|c|c|c|c|}
\hline & $\begin{array}{l}\text { Viewing } \\
\text { function }\end{array}$ & $\begin{array}{l}\text { Viewing } \\
\text { function \& } \\
\text { Comment } \\
\text { function }\end{array}$ & $\begin{array}{l}\text { Viewing } \\
\text { function \& } \\
\text { Button } \\
\text { functions }\end{array}$ & $\begin{array}{l}\text { Viewing function } \\
\& \\
\text { Recommendation } \\
\text { function }\end{array}$ & $\begin{array}{c}\text { Recommendation } \\
\text { function \& } \\
\text { Comment } \\
\text { function }\end{array}$ & $\begin{array}{l}\text { Recommendation } \\
\text { function \& } \\
\text { Button functions }\end{array}$ & $\begin{array}{l}\text { Submission } \\
\text { function }\end{array}$ & $\begin{array}{c}\text { Submission } \\
\text { function \& } \\
\text { Button } \\
\text { functions }\end{array}$ & $\begin{array}{l}\text { Submission } \\
\text { function \& } \\
\text { Viewing } \\
\text { function }\end{array}$ \\
\hline $\begin{array}{l}\text { Somewhat } \\
\text { useful }\end{array}$ & 4.8 & 1.6 & 16.1 & 19.4 & 0.0 & 1.6 & 3.2 & 0.0 & 0.0 \\
\hline $\begin{array}{l}\text { Can't say } \\
\text { either way }\end{array}$ & 3.2 & 0.0 & 1.6 & 8.1 & 0.0 & 0.0 & 0.0 & 0.0 & 0.0 \\
\hline
\end{tabular}




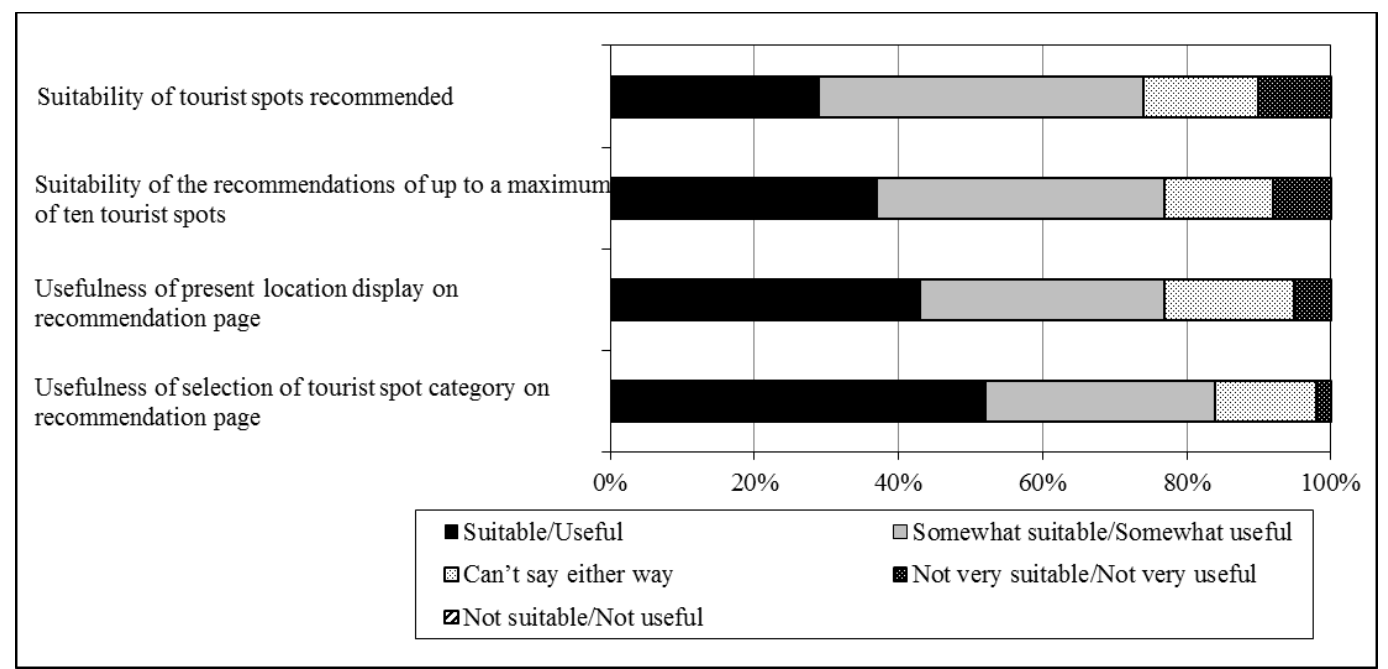

Fig. 5. Results for responses to four question items concerning recommendation function

Note: The response options shown on the right in the explanatory notes in the figure are for the two question items on usefulness - the usefulness of the present location display on the recommendation page, and the usefulness of tourist spot category selection on the recommendation page.

TABLE VI shows the ten pages with the most number of visits from each type of information terminal. Visits from both PCs and mobile information terminals were mainly to the viewing page and the recommendation page. Meanwhile, it can be seen that there were visits from mobile information terminals to the viewing page and the recommendation page for PCs, and the number of visits to the submission page from PCs was more than twice the number of visits to the submission page from mobile information terminals. Further, pages for viewing detailed information on individual tourist spots (Uchikipan Bakery and Red Brick Park) are in the list of the top ten most visited pages for PCs, but not in the list of the top ten most visited pages for mobile information terminals. Therefore, comparing use of the system from PCs to that from mobile information terminals, it is thought that there was more use of the system for submitting information on tourist spots and viewing detailed information on tourist spots from PCs than there was from mobile information terminals. Further, it is thought that users accessing the system from mobile information terminals mainly visited the viewing page and the recommendation page, and often used the system to obtain simple information about tourist spots.

\section{2) Evaluation focusing on submitted information}

TABLE VII shows how many pieces of information were submitted to each tourist spot category from among the 232 pieces of information submitted. Looking at the results by category, there were many submissions concerning restaurants and cafes -75 (about $32 \%$ of the total); however, submissions of information were made in all categories. Therefore, it can be said that a variety of tourist spot information was submitted, and in line with the aim of the system, information for recommending tourist spots suited to the preferences of each user was accumulated.

\section{Identification of measures to improve the system}

Based on the results of the evaluation outlined in this session, in order to more effectively support people taking tourist trips, operation of the following two functions can be proposed.

\section{- Routing function}

This function would enable display of a route to a recommended tourist spot from the user's present location or from any location specified by the user. Further, by linking routes between multiple recommended tourist spots, it would enable them to be displayed as a tourist route. Through this, it can be anticipated that users will be able to plan tourist trips taking into account travel time and travel methods.

- Additional function for viewing page

It is proposed that the display method be changed such that on the page for viewing detailed information about tourist spots, the tourist spot being viewed stands out on the digital map. Further, it is proposed that categories such as "For families", "For groups", and "For solo travel" be added to the category divisions for submissions of information, to enable viewing of submitted information that is even more suited to the behavioral characteristics of each user.

\section{CONCLUSION}

The conclusion of the present study can be summarized into the following three points.

(1) As an information system for recommending tourist spots, a social recommendation GIS which integrated three applications - an SNS, a Web-GIS, and a recommendation system - was designed and developed. Developing a system which integrated these applications enabled constraints concerning information inspection by users, time and spatial constraints, and constraints concerning continuous operation of the system to be eased. The central part of Yokohama City in Kanagawa Prefecture was selected as the region for operation, and system details were configured after a survey of present conditions was carried out. 


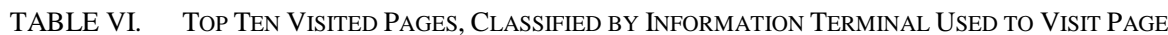

\begin{tabular}{|c|c|c|c|}
\hline \multicolumn{4}{|l|}{ PC } \\
\hline Rank & Page name & Number of visits & Percentage $(\%)$ \\
\hline 1 & Initial page & 257 & 11.1 \\
\hline 3 & Recommendation page (Category selection) & 138 & 6.0 \\
\hline 4 & Submission page & 97 & 4.2 \\
\hline 7 & My information page & 81 & 3.5 \\
\hline 8 & Initial page (for mobile information terminals) & 59 & 2.6 \\
\hline 9 & Tourist spot detailed information viewing page (Uchikipan Bakery) & 23 & 1.0 \\
\hline 10 & Tourist spot detailed information viewing page (Red Brick Park) & 19 & 0.8 \\
\hline
\end{tabular}

Mobile information terminals

\begin{tabular}{|c|c|c|c|}
\hline Rank & Page name & Number of visits & Percentage $(\%)$ \\
\hline 1 & Initial page & 212 & 17.4 \\
\hline 2 & Initial page (for mobile information terminals) & 94 & 7.7 \\
\hline 4 & Recommendation page (Category selection) (for mobile information terminals) & 50 & 4.1 \\
\hline 5 & Viewing page & 46 & 3.8 \\
\hline 8 & Submission page (for mobile information terminals) & 38 & 3.1 \\
\hline 9 & Recommendation page (Display of recommendation results) (for mobile information terminals) & 36 & 3.0 \\
\hline 10 & Recommendation page (Display of recommendation results) & 28 & 2.3 \\
\hline \multicolumn{2}{|r|}{ Total } & 1,216 & 100.0 \\
\hline
\end{tabular}

TABLE VII. SubMISSIONS OF INFORMATION, CLASSIFIED By TOURIST SPOT CATEGORY

\begin{tabular}{|l|r|r|}
\hline \multicolumn{1}{|c|}{ Category } & \multicolumn{1}{c|}{$\begin{array}{c}\text { Number of } \\
\text { submissions }\end{array}$} & Percentage (\%) \\
\hline Restaurants/Cafes & 75 & 32.3 \\
\hline Other eating/drinking establishments & 11 & 4.6 \\
\hline Noted places/Historic sites & 41 & 17.7 \\
\hline Shopping & 26 & 11.2 \\
\hline Theme parks/Parks & 21 & 9.1 \\
\hline Art galleries/Museums & 22 & 9.5 \\
\hline Scenery & 15 & 6.5 \\
\hline Other & 21 & 9.1 \\
\hline Total & 232 & 100.0 \\
\hline
\end{tabular}

(2) Operation was to be conducted over a two month period; therefore, prior to operation, an operation test was conducted for two weeks, areas where the system could be improved were identified, and the system was reconfigured. It was intended that the general public who are more than 18 years both in and outside the region for operation would be users of the system. Meanwhile, of the 98 actual users of the system, over $80 \%$ were in their twenties to forties. This is consistent with the fact that the main user base of regular SNSs consists of people in their twenties to forties. Concerning change in the number of users, the number of users one month after the start of operation reached over $90 \%$ of the total number of users for the whole period of operation. The final total number of items of information submitted was 232 .

(3) Results of a questionnaire given to users of the system after it was operated showed that it can be anticipated that the viewing function and the recommendation function in particular will lead to effective support for people taking tourist trips, and also showed the usefulness of having integrated a recommendation system with a Web-GIS and an SNS. Further, access analysis which used log data confirmed that of the total access count, about $35 \%$ of access was from mobile information terminals, so it can be said that the provision of an interface optimized for mobile information terminals proved useful.

An example of a future topic for research is to implement the functions proposed in Section VII.C, in order to support people taking tourist trips more effectively. Another example is to operate the system in other urban tourist areas, boost the 
track record of use of the system, and increase the significance of using the system.

\section{ACKNOWLEDGMENT}

In the operation of the social recommendation GIS and the questionnaires of this study, enormous cooperation was received from those mainly in the Kanto region such as Kanagawa prefecture and Tokyo Metropolis. We would like to take this opportunity to gratefully acknowledge them.

\section{NOTES}

(1) Yokohama City official tourist information site: http://www.welcome.city.yokohama.jp/ja/. (accessed December. 20, 2013). (Website)

(2) Hamatch! SNS: http://sns.hamatch.jp/. (accessed December 15, 2013). (Website)

(3) TripAdvisor: http://www.tripadvisor.jp/. (accessed December 20, 2013). (Website)

(4) MAPPLE Tourist Information: http://www.mapple.net/. (accessed December 20, 2013). (Website)

(5) Jalan Tourist Information: http://www.jalan.net/kankou/. (accessed December 20, 2013). (Website)

(6) (The travel word-of-mouth site "4travel.jp": http://4travel.jp/. (accessed December 20, 2013). (Website)

(7) Foursquare: https://ja.foursquare.com/. (accessed June 25, 2014). (Website)

(8) Facebook Places: https://www.facebook.com/directory/places/. (accessed June 25, 2014). (Website)

\section{REFERENCES}

[1] J. Ishizuka, Y. Suzuki and K. Kawagoe, "Method for searching for similarities in data on movement paths, designed to support sightseeing in Kyoto", The Special Interest Group Technical Reports of Information Processing Society of Japan, CVIM, "Computer Vision and Image Media", 2007(1), pp.17-23, 2007.

[2] Y. Kurata, "Introducing a hot-start mechanism to a web-based tour planner CT-Planner and Increasing its coverage areas", Papers and Proceedings of the Geographic Information Systems Association of Japan, Vol.21, CD-ROM, 2012.

[3] H. Kawamura, Efforts to spread standard tags in Hokkaido tourist information, and the development of kyun-channel, Journal of Digital Practice, Vol.3, No.4, pp.272-280, 2012.

[4] T. Kurashima, T. Iwata, G. Irie and K. Fujimura, Travel Route Recommendation using Geotags on Photo Sharing Service, Technical Report of The Institute of Electronics, Information and Communication Engineers, LOIS, "Life Intelligence and Office Information Systems", Vol.109, No.450, pp.55-60, 2010.

[5] S. Van Canneyt, S. Schockaert, O.V. Laere and B. Dhoedt, "Timedependent recommendation of tourist attractions using Flickr", Proceedings of the 23rd Benelux Conference on Artificial Intelligence, pp.255-262, 2011.

[6] M. Batet, A. Moreno and D. Sánchez, D. Isern and A. Valls, Turist@: Agent-based personalised recommendation of tourist activities, Expert Systems with Applications, Vol.39, No.8, pp.7319-7329, 2012.

[7] H. Uehara, K. Shimada and T. Endo, "Sightseeing location recommendation using tourism information on the Web", Technical
Report of The Institute of Electronics, Information and Communication Engineers, NLC, "Natural langage Understanding and Models of Communication", Vol.112, No.367, pp.13-18, 2012.

[8] C. C. Yu and H. P. Chang, "Personalized location-based recommendation services for tour planning in mobile tourism applications", Proceedings of the 10th International Conference on ECommerce and Web Technologies, pp.38-49, 2009.

[9] J. M. Noguera, M. J. Barranco, R. J. Segura and L. Martinez, "A mobile 3D-GIS hybrid recommender system for tourism", Information Sciences, Vol.215, pp.37-52, 2012.

[10] L. Baltrunas, B. Ludwig, S. Peer and F. Ricci, Francesco, "Contextaware places of interest recommendations for mobile users. Design, User Experience, and Usability", Theory, Methods, Tools and Practice, Lecture Notes in Computer Science, Vol.6769, pp.531-540, 2011.

[11] M. Ye, P. Yin, W. C. Lee and D. L. Lee, Exploiting geographical influence for collaborative point-of-interest recommendation, Proceedings of the 34th International ACM SIGIR Conference on Research and Development in Information Retrieval, pp.325-334, 2011.

[12] J. J. C. Ying, E. H. C. Lu, W. N. Kuo and V. S. Tseng, "Urban point-ofinterest recommendation by mining user check-in behaviors", Proceedings of the ACM SIGKDD International Workshop on Urban Computing, pp.63-70, 2012.

[13] J. Bao, Y. Zheng and M. F. Mokbel, "Location-based and preferenceaware recommendation using sparse geo-social networking data", Proceedings of the 20th International Conference on Advances in Geographic Information Systems, pp.199-208, 2012.

[14] Q. Yuan, G. Cong, Z. Ma, A. Sun and N. M. Thalmann, "Time-aware point-of-interest recommendation", Proceedings of the 36th International ACM SIGIR Conference on Research and Development in Information Retrieval, pp.363-372, 2013.

[15] X. Liu, Y. Liu, K. Aberer andC. Miao, "Personalized point-of-interest recommendation by mining users' preference transition", Proceedings of the 22nd ACM International Conference on Information and Knowledge Management, pp.733-738, 2013.

[16] T. Yanagisawa and K. Yamamoto, "Study on Information Sharing GIS to Accumulate Local Knowledge in Local Communities", Theory and Applications of GIS, Vol.20, No.1, pp.61-70, 2012.

[17] H. Nakahara, T. Yanagisawa and K. Yamamoto, "Study on a Web-GIS to Support the Communication of Regional Knowledge in Regional Communities: Focusing on Regional Residents' Experiential Knowledge", Socio- Informatics, Vol.1, No.2, pp.77-92, 2012.

[18] S. Yamada and K. Yamamoto, "Development of Social Media GIS for Information Exchange between Regions", International Journal of Advanced Computer Science and Applications, Vol.4, No.8, pp.62-73, 2013

[19] T. Okuma and K. Yamamoto, "Study on a Social Media GIS to Accumulate Urban Disaster Information: Accumulation of Disaster Information during Normal Times for Disaster Reduction Measures", Socio-Informatics, Vol.2, No.2, pp.49-65, 2013.

[20] D. Jannach, M. Zanker, A. Felfernig, G. Friedrich, "Recommender Systems: An Introduction", Cambridge University Press, U.K., 2011.

[21] T. Kamishima, "Algorithms for recommender systems (2)", Transactions of Japanese Society of Artificial Intelligence, Vol.23, No.1, pp.89-103, 2008.

[22] Ministry of Internal Affairs and Communications of Japan, "2011 White paper - information and communications in Japan", Tokyo, 2011. 